\title{
Physical activity is independently related to aerobic capacity in cystic fibrosis
}

\author{
H. Hebestreit*, S. Kieser*, S. Rüdiger*, T. Schenk*, S. Junge ${ }^{\#}$, A. Hebestreit*, \\ M. Ballmann", H-G. Posselt ${ }^{\oplus}$ and S. Kriemler
}

ABSTRACT: It is unclear whether a relationship between physical activity (PA) and maximal oxygen uptake $\left(V^{\prime} \mathrm{O}_{2}\right.$, max) exists in cystic fibrosis (CF) and, if so, whether the relationship reflects a direct effect or is mediated by the effects of confounding variables, such as pulmonary or muscle function. The objective of the present study was to determine the relationship between PA and $V^{\prime} \mathrm{O}_{2}$, max in $\mathrm{CF}$ while adjusting for possible influences of confounding factors.

In total, 36 female and 35 male patients with CF from Germany and Switzerland (aged 12-40 yrs, forced expiratory volume in one second (FEV 1 ) 25-107\% predicted) were studied. A Wingate test was employed to measure muscle power. PA was monitored for 7 days and expressed in two ways: 1) average daily accelerometer count (ADAC) and 2) time spent in moderate-to-vigorous PA (MVPA). $V^{\prime} \mathrm{O}_{2}$, max was determined during an incremental cycle exercise test to volitional fatigue.

PA was positively related to $\mathrm{V}^{\prime} \mathrm{O}_{2}$, max. In a multiple linear regression analysis, height, sex, $\mathrm{FEV}$, muscle power and ADAC (additionally explained variance $2.5 \%$ ) or time spent in MVPA (additionally explained variance $3.7 \%$ ) were identified as independent predictors of $V^{\prime} \mathrm{O}_{2}$, max.

In conclusion, high levels of physical activity in addition to good muscular and pulmonary functions are associated with a high aerobic capacity in cystic fibrosis.

\section{KEYWORDS: Activities of daily living, fitness, lung function, muscular exercise}

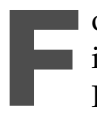

or patients with cystic fibrosis (CF), physical fitness is important in many aspects. First, patients with a high aerobic capacity have a higher life expectancy [1]. Secondly, aerobic capacity correlates with quality-of-life measures [2], and changes in the former are associated with changes in the latter [3]. Finally, in adults with $\mathrm{CF}$, professional achievements are associated with physical fitness [4].

Maximal oxygen uptake $\left(V^{\prime} \mathrm{O}_{2}, \mathrm{max}\right)$, a measure of aerobic exercise capacity, increased with physical training in some studies on patients with $\mathrm{CF}[3,5$, 6]. Thus, it could be assumed that the level of habitual physical activity (PA) in an individual with $\mathrm{CF}$ influences his or her $V^{\prime} \mathrm{O}_{2}$, max. However, some exercise intervention programmes where PA was intentionally increased have failed to raise fitness levels [7, 8]. Furthermore, the only study examining the relationship between PA and $V^{\prime} \mathrm{O}_{2}$, max in CF found no correlation between the reported time spent in vigorous activities and $V^{\prime} \mathrm{O}_{2}$, max in 30 patients aged 7-17 yrs [9]. Only in a subgroup of 10 patients with the lowest lung function (forced expiratory volume in one second (FEV1) $<80 \%$ ) was an association between vigorous

For editorial comments see page 678 .
PA and $V^{\prime} \mathrm{O}_{2}$, max observed. Since impaired lung function (and related factors such as frequency of pulmonary infections) may limit $V^{\prime} \mathrm{O}_{2}$, max as well as physical activities [10-16], it is not clear whether the reported association between the two reflects a true cause-effect relationship or simply the limitation of both by impaired lung function.

Like lung function, body composition and muscle power are related to $V^{\prime} \mathrm{O}_{2}$, max in $\mathrm{CF}[15,16]$ and all might be positively affected by PA and regular exercise [3, 17, 18]. A positive relationship between PA and $V^{\prime} \mathrm{O}_{2}$, max in CF, if it should exist, might thus be mediated by an effect of PA on body composition, muscle mass and muscle power, and may not reflect a direct effect on $V^{\prime} \mathrm{O}_{2}$, max itself.

The objective of the present study was to describe the relationship between $\mathrm{PA}$ and $V^{\prime} \mathrm{O}_{2}$, max in a large group of patients with $\mathrm{CF}$, first without and then after controlling for the effects of possible confounding factors, such as anthropometric variables, age, sex, lung function and muscle power. It was hypothesised that PA would be related to $V^{\prime} \mathrm{O}_{2}$, max in a large heterogeneous group of patients, but that no correlation would be observed when controlling for the effects of body size and composition, lung function and short-term muscle power.
AFFILIATIONS

*University Children's Hospital, Julius-Maximilians-Universität Würzburg, Würzburg,

\#Paediatric Dept, Medizinische Hochschule Hannover, Hannover, 'Paediatric Dept, Johann Wolfgang Goethe Universität, Frankfurt, Germany.

${ }^{+}$Exercise Physiology, Swiss Federal Institute of Technology and University of Zurich, Zurich, Switzerland.

CORRESPONDENCE

H. Hebestreit

Universitäts-Kinderklinik Josef-Schneider-Str. 2 97080 Würzburg

Germany

Fax: 4993120127242

E-mail: hebestreit@mail.uni-

wuerzburg.de

Received:

November 032005

Accepted after revision:

June 082006

\section{SUPPORT STATEMENT}

This study was supported by grants from the Mukovsizidose e.V. and the Swiss CF foundation.

European Respiratory Journal Print ISSN 0903-1936 Online ISSN 1399-3003 


\section{MATERIALS AND METHODS}

\section{Study subjects}

Patients diagnosed with $C F$ and aged $\geqslant 12$ yrs were recruited from CF centres in Germany (Frankfurt, Hannover and Würzburg; $n=37$ ), and Switzerland (Basel, Bern and Zurich; $\mathrm{n}=34$ ). Patients' characteristics are summarised in table 1.

Patients were stable at the time of the study and those with medical problems precluding maximal exercise testing were excluded. The study protocol was approved by the Ethics Committees of all participating centres and written consent was obtained for each subject.

\section{Study design and methods}

After familiarisation with procedures, height and body mass were determined in light exercise clothing without shoes, and skin-fold thickness was measured as described by LOHMAN et al. [19]. Percentage body fat (\%BF) was calculated from skinfold thickness using the equations provided by SLAUGHTER et al. [20] for patients aged $<16$ yrs, and the equations published by DURNIN and WOMERSLEY [21] for older patients. FEV1 and forced vital capacity (FVC) were determined by standard spirometry (Masterscreen Body; Jaeger, Würzburg, Germany) and expressed as \% predicted (\% pred) [22].

Each patient completed a Wingate test on a calibrated, mechanically braked cycle ergometer [23]. In all German centres, the identical Monark 834 E Ergomedic ergometer

\section{TABLE 1 Subjects' characteristics}

\section{Characteristics}

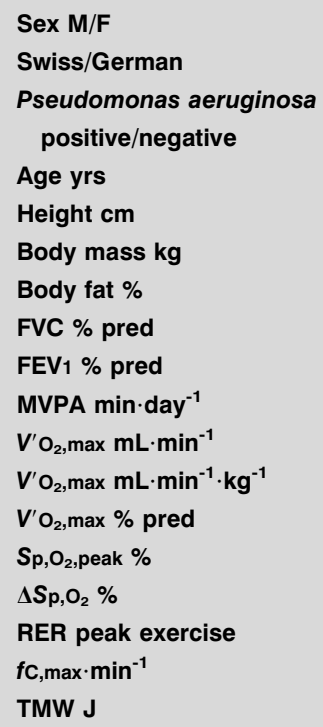

$35 / 36$

$34 / 37$

[52/19]

$20.5 \pm 6.0(12.2-40.0)$

$53.8 \pm 10.8(30.0-86.0)$

$15.9 \pm 7.2(2.9-30.4)$

$79.8 \pm 17.8(37.0-117.9)$

$66.0 \pm 21.1(25.3-107.4)$

$85.1 \pm 36.1$ (10.0-175.9)

$2004 \pm 549$ (761-3333)

$37.5 \pm 8.1(19.3-55.0)$

$79.4 \pm 17.2(37.2-120.2)$

$-4.0 \pm 3.5(-13-1)$

$1.08 \pm 0.11(0.83-1.30)$

$180 \pm 11(153-200)$

$10379 \pm 3335$ (5040-19904)
$166 \pm 9(139-187)$

$92.8 \pm 4.9(92-100)$

Data are presented as $n$ or mean \pm SD (range). M: male; F: female; FVC: forced vital capacity; \% pred: \% predicted; FEV1: forced expiratory volume in one second; MVPA: moderate and vigorous physical activity; $V^{\prime} \mathrm{O}_{2}$,max: maximal oxygen uptake; $\mathrm{Sp}, \mathrm{O}_{2}$,peak: arterial oxygen saturation at peak exercise; $\Delta \mathrm{Sp}, \mathrm{O}_{2}$ : change in oxygen saturation from rest to peak exercise; RER: respiratory exchange ratio; $f \mathrm{C}$,max: maximum cardiac frequency during the incremental cycling task; TMW: total mechanical work during the Wingate test.
(Monark Exercise $\mathrm{AB}$, Varberg, Sweden) was employed. In Switzerland, all testing was performed at one location in Zurich using a Fleisch ergometer (Fleisch, Metabo, Switzerland). For each patient, braking force was calculated from body mass using existing equations [24] and modified by up to $10 \%$ depending on the performance in two short practice runs. The reason for this adjustment was to identify a braking force that would elicit the highest total mechanical work (TMW) during the 30-s test. TMW generated during the Wingate test was chosen as indicator of muscle power.

After $\geqslant 30 \mathrm{~min}$ of rest, subjects completed a continuous incremental cycling task to volitional fatigue [25]. Work rate was increased every minute by $15-20 \mathrm{~W}$, depending on patient's height and physical fitness. All German patients were tested using the identical calibrated Monark 834 E cycle ergometer and metabolic cart (CPX/D; MedGraphics, St Paul, MN, USA). All testing of the Swiss patients employed an electronically braked ergometer (Ergoline 800c; Pilger, St Gallen, Switzerland) and a Quark B2 metabolic cart (Cosmed, Rome, Italy). Both metabolic carts were calibrated before each exercise test with two gases of known concentrations $\left(21 \% \mathrm{O}_{2}\right.$, $79 \% \mathrm{~N}_{2} ; 12 \% \mathrm{O}_{2}, 5 \% \mathrm{CO}_{2}, 81 \% \mathrm{~N}_{2}$ ). Stability of the $\mathrm{O}_{2}$ and $\mathrm{CO}_{2}$ sensors was verified after each test. $V^{\prime} \mathrm{O}_{2}$,max was determined as the highest oxygen uptake over $30 \mathrm{~s}$ during the test and was normalised for body weight. $V^{\prime} \mathrm{O}_{2}$, max was also expressed as \% pred [26]. Arterial oxygen saturation $\left(\mathrm{Sp}_{1} \mathrm{O}_{2}\right)$ was monitored during the exercise test using pulse oximetry (Nellcor Reflectance oxygen sensor RS10; Nellcor Puritan Bennet Inc., Pleasanton, CA, USA).

PA was monitored for 7 days using the MTI/CSA 7164 accelerometer (MTI Health Services, Fort Walton Beach, FL, USA). Periods of $\geqslant 60 \mathrm{~min}$ with zero readings were excluded from analysis. All subjects completed at least 5 days of recordings with $\geqslant 10 \mathrm{~h}$ of valid data per day. Activity was expressed in two ways: 1) average accelerometer count per day as an unmodified, measured variable; and 2) daily time spent in moderate and vigorous physical activities (MVPA). As there are no validation studies for the MTI/CSA 7164 or any other accelerometer in patients with $\mathrm{CF}$, time spent in MVPA was somewhat arbitrarily defined as the average number of minutes per day with a recording $>1,000$ counts $\cdot \mathrm{min}^{-1}$. In healthy subjects, a value of 191 counts $\cdot \mathrm{min}^{-1}$ was reported for the MTI/CSA 7164 as a cut-off point distinguishing between light and moderate activities, if a variety of activities were included in the validation [27]. If only walking and jogging are employed for the validation, cut-off points of $\sim 2,000$ counts. $\min ^{-1}$ have been published [27, 28]. Of the present authors' patients, a considerable number of activities, although not all, included walking, jogging or running; thus, the cut-off point was set to 1,000 counts $\cdot \mathrm{min}^{-1}$.

\section{Data analysis}

To analyse the relationship between PA (average accelerometer counts per day and time spent in MVPA) and $V^{\prime} \mathrm{O}_{2}$, max $\left(\mathrm{mL} \cdot \mathrm{min}^{-1} \cdot \mathrm{kg}^{-1}\right.$ and \% pred), linear regression analyses were performed and correlation coefficients were computed.

The regression analyses were repeated using a multiplicative, allometric approach [29-31] to eliminate possible effects of body size, and pulmonary and muscle function from the 
relationship between $V^{\prime} \mathrm{O}_{2}$, max and PA. This approach is based on the assumption that $V^{\prime} \mathrm{O}_{2}$, max is not linearly related to measures of body size, e.g. body mass $\mathrm{M}$, but is proportional to power functions of those measures, e.g. $\mathrm{M}$ to the power of an exponent $x$. Further covariates, such as age, can be incorporated in the multiplicative equation as additional factors (e.g. $\left.V^{\prime} \mathrm{O}_{2}, \max =\mathrm{a} \cdot \mathrm{M}^{\mathrm{x}} \cdot \mathrm{e}^{\mathrm{y} \cdot \mathrm{age}}\right)$, where $\mathrm{a}$ and $\mathrm{e}^{\mathrm{y}}$ are coefficients. By logtransforming the model equation, an additive equation is generated $\left(\ln \left(V^{\prime} \mathrm{O}_{2}, \max \right)=\ln (\mathrm{a})+\mathrm{x} \cdot \ln (\mathrm{M})+\mathrm{y} \cdot\right.$ age $)$, which can be fitted to the data set by multiple linear regression analysis. There is both theoretical and experimental evidence supporting the use of this approach [30,31]. Briefly, additive linear regression models have been challenged for two reasons. 1) Using an additive regression model with a positive intercept implies that, for example, a "hypothetical" individual with a body weight of $0 \mathrm{~kg}$ may have a performance which is not zero. This "observation" would be contrary to common sense. 2) Residuals over the additive predictor-performance regression model increase with increasing values of the predictor. In other words, the error over the regression is not additive but multiplicative. This observation is in contrast to the conditions for regression analysis.

For the allometric multiple regression analyses, the natural logarithm of $V^{\prime} \mathrm{O}_{2}$, max was computed for each individual and
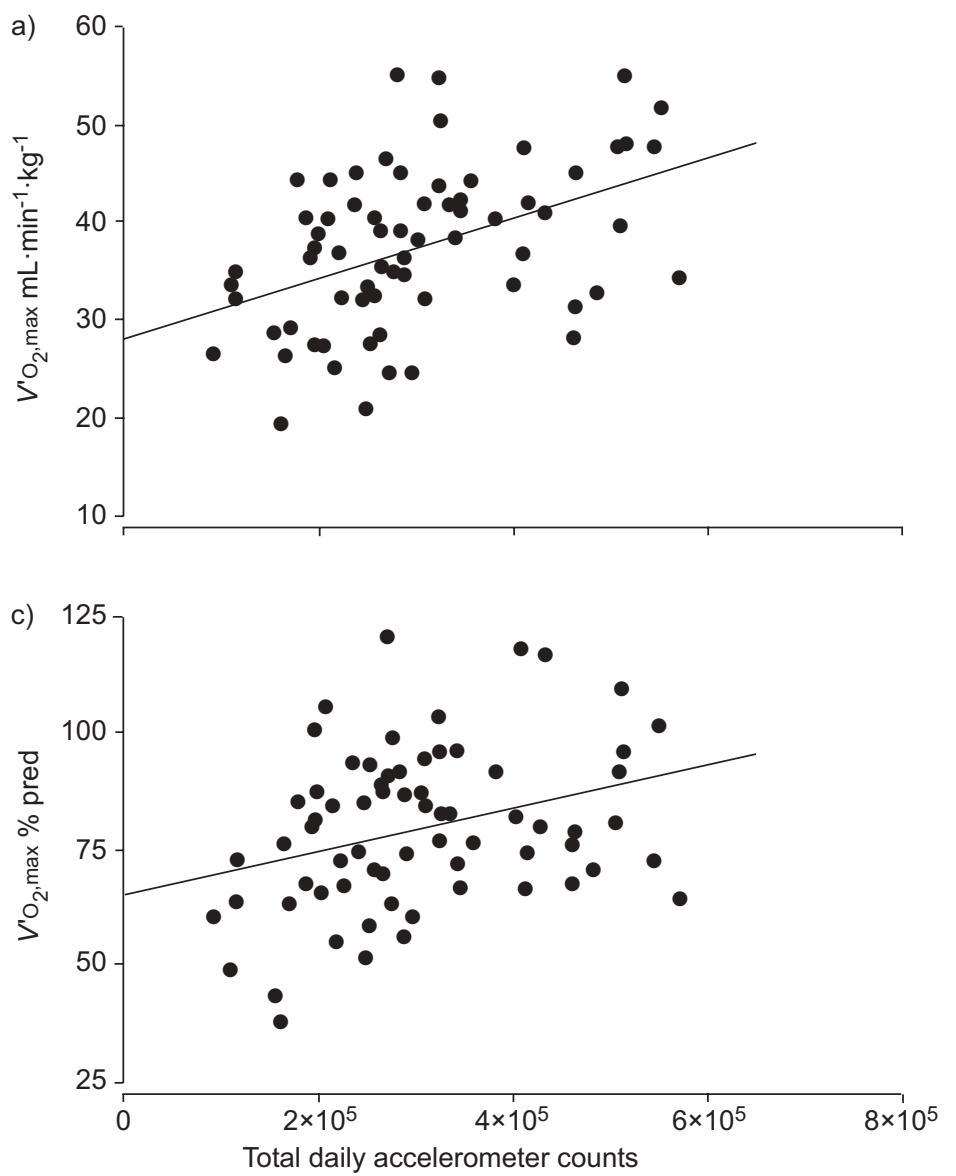

entered as a dependent variable in multiple linear regression analyses. Two separate analyses were performed, one with average accelerometer count per day (model 1) and one with time spent in MVPA (model 2) allowed to enter the model. For both analyses, the following additional variables were allowed to enter the prediction equations as independent predictors of $\ln \left(V^{\prime} \mathrm{O}_{2}\right.$,max): nationality (German or Swiss, to account for possible differences in laboratory and experimental configuration), sex, age, age ${ }^{2}$, age $\times$ sex, $\ln$ (height), $\ln$ (body mass), $\%$ body fat, FVC (\% pred), FEV1 (\% pred), $\ln (\mathrm{TMW}), \mathrm{Sp}_{\mathrm{p}} \mathrm{O}_{2}$ at peak exercise, change in $\mathrm{Sp}, \mathrm{O}_{2}$ from rest to exercise, and Pseudomonas status.

After all significant predictors had been entered into model 1 or 2, average daily accelerometer count or time spent in MVPA were excluded from the respective model and the change in explained variance of $\ln \left(V^{\prime} \mathrm{O}_{2}\right.$, max $)$ was calculated. Significance was accepted at $\mathrm{p}<0.05$.

\section{RESULTS}

$V^{\prime} \mathrm{O}_{2}$,max expressed relative to body weight and as a percentage of predicted was significantly related to the average daily accelerometer count and MVPA (fig. 1).

In model 1 , the multiple regression analysis including average accelerometer count per day as measure of PA, five

b)

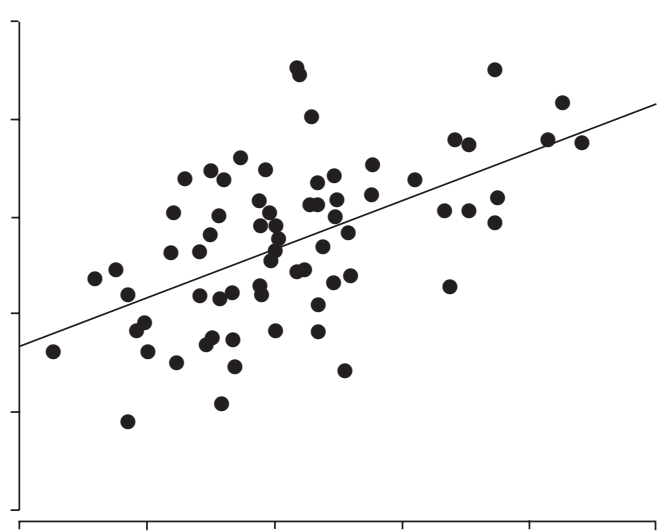

d)

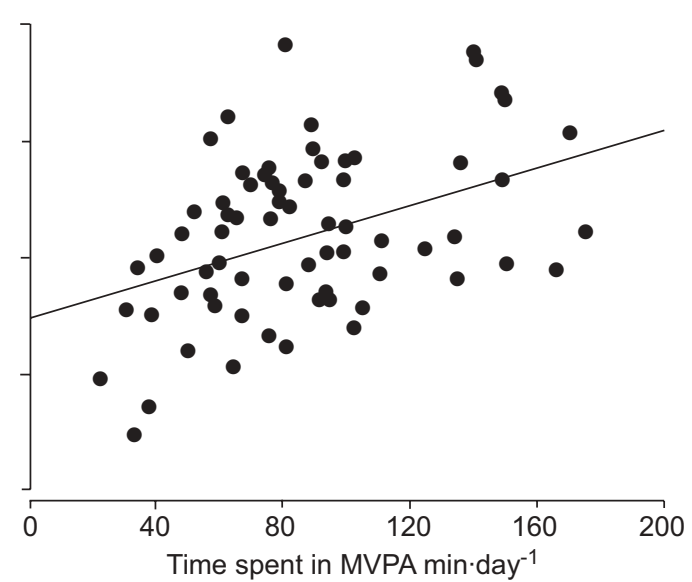

FIGURE 1. Relationship between physical activity ( $a$ and $c$ : total daily accelerometer count; $b$ and $d$ : time spent in moderate-to-vigorous activities (MVPA) per day) and maximal oxygen uptake $\left(V^{\prime} \mathrm{O}_{2}\right.$,max) expressed relative to body weight $(\mathrm{a}$ and $\mathrm{b})$ and as a percentage of predicted (\% pred; $\mathrm{c}$ and d) in 71 patients with cystic fibrosis. The relationship between physical activity and $V^{\prime} \mathrm{O}_{2}$, max is significant irrespective of the way either variable is expressed. a) $\left.\left.r=0.45, p<0.001 ; b\right) r=0.55, p<0.001 ; c\right) r=0.32$, $p<0.01 ;$ d) $r=0.42, p<0.001$ 
TABLE 2 Significant independent predictors of In(maximal oxygen uptake $\left.\left(V^{\prime} \mathrm{O}_{2}, \max \right)\right)$ in patients with cystic fibrosis ${ }^{\#}$

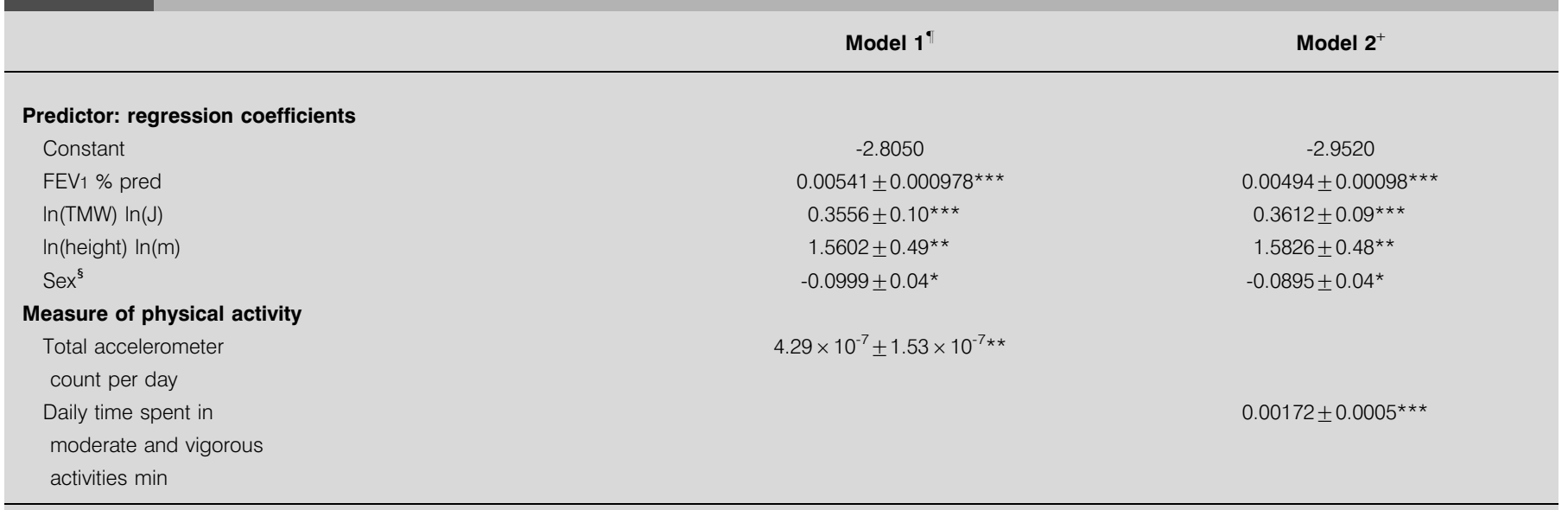

Data are presented as regression coefficients $\pm \mathrm{SE}$, unless otherwise indicated. FEV1: forced expiratory volume in one second; TMW: total mechanical work. \#: the multiple

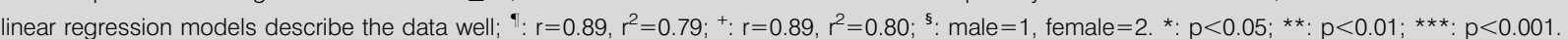

independent predictors of $\ln \left(V^{\prime} \mathrm{O}_{2}, \max \right)$ entered the model in the following order: $\ln (\mathrm{TMW}), \mathrm{FEV} 1$, average accelerometer count per day, $\ln$ (height) and sex. Once these predictors had entered the equation, none of the other variables could significantly add to the prediction of $\ln \left(V^{\prime} \mathrm{O}_{2}, \max \right)$.

When using time spent in MVPA as the activity variable allowed to enter the equation (model 2), the same additional predictors were identified as in model 1 . However, time spent in MVPA entered the equation at the second step of the analysis, after $\ln (\mathrm{TMW})$ and before $\mathrm{FEV} 1, \ln$ (height) and sex were included.

Table 2 summarises the regression coefficients of both models, as determined from the multiple regression analyses. The coefficients reported in table 2 are exponents relating $V^{\prime} \mathrm{O}_{2}$, max to FEV1, TMW, height and sex. In other words, $V^{\prime} \mathrm{O}_{2}$, $\max$ in model 1 was proportional to height ${ }^{1.5602}$, $\mathrm{TMW}^{0.3556}$, $\mathrm{e}^{0.00541 \cdot \mathrm{FEV} 1}, \mathrm{e}^{-0.0999 \cdot \mathrm{sex}}$ and $\mathrm{e}^{0.000000429 \cdot \text { average accelerometer count per }}$ day in the present group of patients with CF. In model 2, $V^{\prime} \mathrm{O}_{2}$, max was proportional to height ${ }^{1.5826}, \mathrm{TMW}^{0.3612}, \mathrm{e}^{0.00494}$. FEV1, $\mathrm{e}^{-0.0895 \cdot \operatorname{sex}}$ and $\mathrm{e}^{0.00172 \cdot \text { time spent in MVPA }}$.

Removing the average accelerometer count per day as a predictor of $\ln \left(V^{\prime} \mathrm{O}_{2}, \max \right)$ in model 1 reduced the explained variance of $\ln \left(V^{\prime} \mathrm{O}_{2}, \max \right)$ by $2.5 \%$, from 78.5 to $76.0 \%$. The explained variance of $\ln \left(V^{\prime} \mathrm{O}_{2}\right.$, max $)$ was reduced by $3.7 \%$ when time spent in MVPA was removed from model 2.

\section{DISCUSSION}

The current study shows that PA and aerobic capacity are related in patients with CF. At first, this finding does not seem surprising. However, only one study has previously assessed this relationship [9] and could not detect a significant correlation in a group of 30 patients with CF. In this latter study [9], only in the 10 patients with reduced pulmonary functions $\left(\mathrm{FEV} 1<80 \%\right.$ ) were $\mathrm{PA}$ and $V^{\prime} \mathrm{O}_{2}$, max related. It is possible that the larger sample size in the present study, which also included adult subjects, the more advanced pulmonary disease of the subjects, and the more objective method of measuring PA (accelerometry versus activity questionnaire) allowed detection of the relationship. For the first time, it has been possible to show that $V^{\prime} \mathrm{O}_{2}$, max is related to PA when the effects of body size, sex, lung function and muscle power are taken into account. Most of these factors are related to both PA and $V^{\prime} \mathrm{O}_{2}$, max and, thus, this could explain the relationship between them. Since the analysis revealed a significant relationship between $\mathrm{PA}$ and $V^{\prime} \mathrm{O}_{2}$, max when the abovementioned factors were accounted for, an effect of PA on $V^{\prime} \mathrm{O}_{2}$, max is shown that is not mediated by sex, lung function or muscle mass and function.

Several studies have shown that the enhancement of PA may improve $V^{\prime} \mathrm{O}_{2}$, max in patients with CF $[5,17,32]$. Therefore, it is very likely that a high level of $\mathrm{PA}$ is beneficial for a high $V^{\prime} \mathrm{O}_{2}$, max. However, it cannot be excluded that $V^{\prime} \mathrm{O}_{2}$, max also influences PA. Associations between $V^{\prime} \mathrm{O}_{2}$, max and quality-oflife measures, such as physical functioning and body image, have been reported [33], and these may translate into positive attitudes towards physical activities in those patients who have a relatively high $V^{\prime} \mathrm{O}_{2}$, max.

Multiple linear regression analysis using a multiplicative model identified body height, sex, FEV1 and muscle power (in addition to PA) as independent, significant predictors of $V^{\prime} \mathrm{O}_{2}$,max. This finding is in line with the results of several studies in patients with CF showing that aerobic performance defined as $V^{\prime} \mathrm{O}_{2}$, max is correlated with measures of lung function [11, 13-15] and muscle power [16]. In healthy people, $V^{\prime} \mathrm{O}_{2}$, max is related to age, sex, height, weight and body composition [34, 35].

Only one study has evaluated the effects of several independent predictors on $V^{\prime} \mathrm{O}_{2}$, max in $\mathrm{CF}$, employing a multiple linear regression analysis [16]. In that study, lean body mass, FEV1 and 30-s sprint work were allowed to enter the regression equation. Although lean body mass was significantly correlated with $V^{\prime} \mathrm{O}_{2}$, max in a simple linear regression analysis, the best model included only FEV1 and the work generated during the 30-s sprint. The present results are in line with these 
findings, but extend the number of significant independent predictors of $V^{\prime} \mathrm{O}_{2}$, max beyond those described by LANDS et al. [16] by also including PA, sex and height. Again, both the latter variables are well known to correlate with aerobic capacity in healthy individuals [34, 35].

There are several factors not included in the measurements made in the present study which might explain the relationship between PA and $V^{\prime} \mathrm{O}_{2}$, max, even after adjustment for body size, sex, lung function and muscle power. For example, cardiovascular function and enzyme activities involved in oxidative metabolism were not directly measured in the current study. There may well be an effect of endurance-type physical activities on these parameters, which translates into an increase in $V^{\prime} \mathrm{O}_{2}$, max. Furthermore, the effect of physical activities on $V^{\prime} \mathrm{O}_{2}$, max may be mediated via a strengthening of respiratory muscles. In patients with chronic obstructive pulmonary disease, an exercise rehabilitation programme resulted in an increase in inspiratory muscle force and $V^{\prime} \mathrm{O}_{2}$,max, but no improvements in FEV1 [36].

In conclusion, physical activity is a significant, although relatively weak, predictor of maximal oxygen uptake in cystic fibrosis, even when the effects of body size, sex, lung function and short-term muscle power are taken into account. Therefore, an increase in physical activity may translate into an increase in maximal oxygen uptake independently of improvements in muscle power and lung function.

\section{REFERENCES}

1 Nixon PA, Orenstein DM, Kelsey SF, Doershuk CF. The prognostic value of exercise testing in patients with cystic fibrosis. N Engl J Med 1992; 327: 1785-1788.

2 Orenstein DM, Nixon PA, Ross EA, Kaplan RM. The quality of well-being in cystic fibrosis. Chest 1989; 95: 344-347.

3 Selvadurai HC, Blimkie CJ, Meyers N, Mellis CM, Cooper PJ, Van Asperen PP. Randomized controlled study of in-hospital exercise training programs in children with cystic fibrosis. Pediatr Pulmonol 2002; 33: 194-200.

4 Frangolias DD, Holloway CL, Vedal S, Wilcox PG. Role of exercise and lung function in predicting work status in cystic fibrosis. Am J Respir Crit Care Med 2003; 167: 150-157.

5 Orenstein DM, Franklin BA, Doerchuk CF, et al. Exercise conditioning and cardiopulmonary fitness in cystic fibrosis. The effects of a three-month supervised running program. Chest 1981; 80: 392-398.

6 Moorcroft AJ, Dodd ME, Morris J, Webb AK. Individualized unsupervised exercise training in adults with cystic fibrosis: a 1 year randomized controlled trial. Thorax 2004; 59: 1074-1080.

7 Schneiderman-Walker J, Pollock SL, Corey M, et al. A randomized controlled trial of a three year home exercise program in cystic fibrosis. J Pediatr 2000; 136: 304-310.

8 Holzer FJ, Schnall R, Landau LI. The effect of a home exercise programme in children with cystic fibrosis and asthma. Aust Paediatr J 1984; 20: 297-301.

9 Nixon PA, Orenstein DM, Kelsey SF. Habitual physical activity in children and adolescents with cystic fibrosis. Med Sci Sports Exerc 2001; 33: 30-35.

10 McKone EF, Barry SC, FitzGerald MX, Gallagher CG. Role of arterial hypoxemia and pulmonary mechanics in exercise limitation in adults with cystic fibrosis. I Appl Physiol 2005; 99: 1012-1018.

11 Shah AR, Gozal D, Keens TG. Determinants of aerobic and anaerobic exercise performance in cystic fibrosis. Am J Respir Crit Care Med 1998; 157: 1145-1150.

12 Selvadurai HC, Blimkie CJ, Cooper PJ, Mellis CM, Van Asperen PP. Gender differences in habitual activity in children with cystic fibrosis. Arch Dis Child 2004; 89: 928-933.

13 Freeman W, Stableforth DE, Cayton RM, Morgan MDL. Endurance exercise capacity in adults with cystic fibrosis. Respir Med 1993; 87: 541-549.

14 Marcotte JE, Grisdale RK, Levison H, Coates AL, Canny GJ. Multiple factors limit exercise capacity in cystic fibrosis. Pediatr Pulmonol 1986; 2: 274-281.

15 Klijn PHC, van der Net J, Kimpen JL, Helders PJM, van der Ent CK. Longitudinal determinants of peak aerobic performance in children with cystic fibrosis. Chest 2003; 124: 2215-2219.

16 Lands LC, Heigenhauser GJF, Jones NL. Analysis of factors limiting maximal exercise performance in cystic fibrosis. Clin Sci 1992; 83: 391-397.

17 Klijn PH, Oushoorn A, van der Ent CK, van der Net J, Kimpen JL, Helders PJ. Effects of anaerobic training in children with cystic fibrosis: a randomized controlled study. Chest 2004; 125: 1299-1305.

18 Schneiderman-Walker J, Wilkes DL, Strug L, et al. Sex differences in habitual physical activity and lung function decline in children with cystic fibrosis. J Pediatr 2005; 147: 321-326.

19 Lohman TG, Roche AF, Martorell R. Anthropometric standardization reference manual. Champaign, IL, Human Kinetics, 1991.

20 Slaughter MH, Lohman TG, Boileau RA, et al. Skinfold equations for estimation of body fatness in children and youth. Hum Biol 1988; 60: 709-723.

21 Durnin JVGA, Womersley J. Body fat assessed from total body density and its estimation from skinfold thickness: measurements on 481 men and women aged from 16 to 72 years. Br J Nutr 1974; 32: 77-97.

22 Sherrill DL, Lebowitz MD, Knudson RJ, Burrows B. Continuous longitudinal regression equations for pulmonary function measures. Eur Respir J 1992; 5: 452-462.

23 Hebestreit H, Mimura K, Bar-Or O. Recovery of muscle power after high-intensity short-term exercise: comparing boys and men. J Appl Physiol 1993; 21: 1-6.

24 Dotan R, Bar-Or O. Load optimization for the Wingate anaerobic test. Eur J Appl Physiol 1983; 51: 409-417.

25 Godfrey S, Davies CTM, Wozniak E, Barnes CA. Cardiorespiratory response to exercise in normal children. Clin Sci 1971; 40: 419-431.

26 Orenstein DM. Assessment of exercise pulmonary function. In: Rowland TW, ed. Pediatric Laboratory Exercise Testing. Clinical Guidelines. Champaign, IL, Human Kinetics, 1993; pp. 141-163.

27 Hendelman D, Miler K, Baggett C, Debold E, Freedson P. Validity of accelerometry for the assessment of moderate intensity physical activity in the field. Med Sci Sports Exerc 2000; 32: Suppl. 9, S442-S449.

28 Freedson PS, Melannson E, Sirard J. Calibration of the Computer Science and Applications, Inc. accelerometer. Med Sci Sports Exerc 1998; 30: 777-781. 
29 Nevill AM, Holder RL, Baxter-Jones A, Round JM, Jones DA. Modeling developmental changes in strength and aerobic power in children. J Appl Physiol 1998; 84: 963-970.

30 Welsman JR. Interpreting young peoples' exercise performance: sizing up the problem. In: Armstrong N, Kirby BJ, Welsman JR, eds. Children and Exercise XIX. Promoting Health and Well-Being. London, E \& FN Spon, 1997; pp. 191-203.

31 Nevill AM. The appropriate use of scaling techniques in exercise physiology. Ped Exerc Sci 1997; 9: 295-298.

32 Hebestreit A, Kriemler S, Kieser S, et al. Effects of different conditioning programs on aerobic capacity in CF. Pediatr Pulmonol 2003; 36: Suppl. 25, 329.
33 Klijn PH, Niuwenhuis M, van Stel H, et al. Validation of the Dutch pediatric cystic fibrosis quality of life questionnaire. In: Klijn PHC, ed. Physical fitness and quality of life in children with cystic fibrosis. Utrecht, PHC Klijn, 2003; pp. 41-57.

34 Armstrong N, Welsman JR, Chia MY. Short term power output in relation to growth and maturation. $\mathrm{Br} J$ Sports Med 2001; 35: 118-124.

35 Nevill AM, Holder RL. Modelling maximum oxygen uptake: a case study in non-linear regression formulation and comparison. Appl Statist 1994; 43: 653-666.

36 Troosters T, Gosselink R, Decramer M. Short- and longterm effects of outpatient rehabilitation in patients with chronic obstructive pulmonary disease: a randomized trial. Am J Med 2000; 109: 207-212. 